\title{
Analysis of the Development Trend of the Managerial Science and Engineering with Bibliometric
}

\author{
Jing-Yi Wang ${ }^{1, a}$,Yuan Run ${ }^{1, b}$ \\ ${ }^{1}$ Science and Technology Information Institute, Jiangsu University,201013, China \\ aemail: 370036517@qq.com, bemail:yuan run@ujs.edu.cn
}

Keywords: Managerial science and engineering,Bibliometric analysis, Comparative analysis

\begin{abstract}
This paper reviews the current situation and trend of managerial science and engineering with bibliometric, in which the discussion of this development trend and research focus is especially made. Some opinions and suggestions are put forward for dynamic research on discipline with bibliometric in accordance with the overall summary of the research focus in managerial science and engineering in the last ten years.
\end{abstract}

\section{Introduction}

Management science is a branch of learning which deals with universal objective laws in the research process.And bibliometrics is a cross discipline, which quantitatively analyzes all the knowledge by mathematical and statistical methods. It plays a major role in the logic structure of information science, and is closely associated with the basic theory of science communication.

The discussion about research contents and hotspots at home and abroad in various fields is made with statistical bibliometric analysis in this paper, and the purpose of which is to promote the development of managerial science and engineering and to obtain the application status of bibliometric. The research of managerial science and engineering is faced with new opportunities and challenges in the coming of information and knowledge economics times. Bibliometric can be applied to the study on research focus in management science and the prediction on its development direction as well, which could provide reference for formulating developmental planning to a certain extent. To be specific, some suggestions are put forward by analyzing the recent literature of managerial science and engineering with bibliometrics.

\section{Classification in management science and Basic connotation of related disciplines}

Management is a systematic study of the basic laws of management activities and the general scientific method according to "Lists of Disciplines and Majors of Master, Doctor Degrees, and Post Graduate Education" promulgated by the Ministry of Education and the State Council Academic Degrees Committee in 1997 as well as the subject classification and connotation definitions from NSFC. It includes five first class disciplines, that is, managerial science and engineering, business administration, discipline of management of agricultural and forestry economy, public administration science and library information and archival management. Meanwhile, there are 15 second-degree subjects under the first class disciplines.

Managerial science and engineering is a subject dealing with management issues of society, economy, engineering and other aspects by comprehensive use of systems science, management science, mathematics, economics and behavioral sciences combined with information technology. Library, intelligence and archives administration belong to the first-degree subject under management, which contains three second-degree subjects, namely, library science, information science and archives administration. Library science is the study of the development of the library, organization and management, as well as the laws of science library work. The concept of information science is originated from Europe and the United States. Chinese scholars believe that intelligence is a study of intelligence generation and transmission which keeps the circulation process of intelligence in the best state by the application of rules and modern information 
technology. Archives administration is the discipline which deals with the operation rules of archival information system and the general principle, and the technical method of archival management is also the object of its study. The research content of library science and archives administration are relatively concentrated on certain aspects while the research on interdisciplinary feature of information science appears significantly.

\section{Application Situation of bibliometrics in Managerial Science and Engineering}

Bibliometrics is an important branch of information science. Because it has great value in methodology, and bibliometrics can also be looked as a special study method. It plays a major role in the logic structure of information science, and is closely associated with the basic theory of science communication.

In recent years, bibliometrics has developed rapidly. It is applied to scientific evaluation for managerial science and engineering with increasing frequency. During the "eleventh five-year plan" period, present study situation, research hotspots and trend of development were discussed with bibliometric. In other words, analysis of the development history, development status and development trend of managerial science and engineering could provide reference for formulating developmental planning, selecting innovation projects funded and indicating scientific researchers to choose task.

In the last ten years, many results were obtained from the empirical research on the development trends of management science with bibliometric. The main achievements are as follows:

Based on management science and engineering disciplines code, She and XI, et al [1] statistically analyzed the papers that indexed by China Journal Net from 1994 to 2000 in 44 kinds of professional journals of management science and engineering research field by bibliometric and $\mathrm{k}$ eyword searching. In order to reveal the research and progress of the project management in China recently, Liu [2] analyzed the papers published in Management Engineering Journal as well as the authors, the quoted passages during the period of 1998 2001 statistically. According to the "ordinary college undergraduate professional directory" which was promulgated in the national Ministry of education in July 1998, Zhang, et al.[3] conducted a questionnaire survey of 200 Chinese management experts and scholars, speculation of management science and engineering research status and progress with reference to the University Management Science and Engineering Research rankings. According to the management of scientific classification code prepared by Natural Science Fund Committee, Qunxia Li et al. [4] discussed and compared the management science and engineering research content, hotspots in various fields at home and abroad with bibliometrics. Based on the papers of management science and engineering published in 117 Journals collected by SCI or SSCI in 1994 2004, 77 kinds of domestic chinese journals and the conference of the ISTP international conference index database from 2000 to 2004, Lingling Zhang, et al [5] used bibliometric method to analyze the history of development of management science and engineering disciplines in various fields at home and abroad, current situation and the future research focus, and studied the mainly on the reasons for the formation of hot spot at home and abroad as well as the content of the similarities and differences. Wei Zhang et al. [6] explored a hot issue in management discipline based on the published articles in various fields of keyword search statistics in the past 10 years, he made a comparative study on research characteristics and the formation of hot spots and trends, etc. Shaobo Ji et al. [7] pointed out Chinese IS research status, issues and trends by analyzing the published 18 kinds of chinese academic journals representative for information systems (IS) papers between 1999 to 2003. Shiqiang Mei et al. [8] studied the history and system of management science and engineering disciplines. LiangLiang Wang et al. [9] investigated the trends of abroad management science disciplines based on content analysis. Lanfu Wang, Changming Yang [10] paid attention to the 4537 collection of management science and engineering PhD thesis in "CNKI full-text database of Chinese doctoral thesis". The cluster analysis of high frequency keywords was conduct by taking the keywords which could reflect academic research hot spot as research object. Then the internal relation of high-frequency words 
was obtained and research situation, hotspots or trends of management science and engineering doctoral thesis were investigated as well. Nannan Du, Zong, et al. [11] analyzed the domestic publications from 2000-2011 of management science and engineering subject. They investigated the hot issues and current tendency of management science and engineering research by introducing an optimized method called "common-word analysis" which is more advanced than the "single keyword-frequency" one.

In addition, in order to find out the management discipline development status in our school, the author searches from the management discipline categories for the papers published by school of management of our unit, and 268 papers were found from the year 2000, in which 183 literature works were published in EI source journals, core journals and CSSCI source journals. It is obvious that the management discipline has the small number while the high quality of published papers, for instance, 68\% comes from the core journals. We published 87 management discipline papers in 2013, 147 papers throughout 2012, and 34 papers from 2000 to 2011. There are 57 literatures supported by the National Natural Science Foundation, 42 literatures supported by the National Social Science Fund. From the publications distribution, our management discipline professional developed rapidly in the past two years. From the point of view of discipline, there are 74 papers in business economy, 72 papers in macroeconomic management and the sustainable development, and 32 papers in higher education, etc. From the above, one can see that management disciplines in our unit focus on business administrations and more research papers published. We also find 6 papers in library as well as information and digital library disciplines published from 2012 to 2013 and there are four of them published in core journal of china. It shows that the research in library and information science has become a new direction for management disciplines in recent years.

\section{The development trend and conception of applications of bibliometrics}

Based on the above literature and analysis of "2013 National Natural Science Foundation Proje ct Guide", the hotspots of management science and engineering research has changed obviously in the past 12 years.

From the distributions of NSFC's discipline branches in recent years, one could find that the largest number of applications is still in the areas of operations research and management, which continues with a upward trend (accounting for 18.56\% of total applications and $17.63 \%$ in 2011). The second one is in the areas of information systems and management areas (accounting for total number of $13.65 \%$ and $12.89 \%$ in 2011). The third one is in the financial engineering field (accounting for total number of $8.44 \%$ and $8.45 \%$ in 2011). In addition, the number of applications in industrial engineering and management, management systems engineering, decision theory and methods, risk management techniques and methods are also greater, accounting $7.15 \%, 6.72 \%$, $6.55 \%$ and $6.37 \%$ of the total number.

The previous studies can be divided into three categories broadly. The first method synthesize the two index about the number of research papers published and the growth rate of which into one by weighted average based on discipline code. This method could reflect the theme of each research focus but it needs to be improved with accuracy. Secondly, the research focus is considered from two aspects of the total volume of papers and the content of the thesis using bibliometric or content analysis. This method is unitary and the ability requirement of researcher's own expertise as well as the insight into the capacity is relatively high, which lead the conclusion is coarse. Thirdly, the analysis of the research focus of the discipline applying "single keyword-frequency" method and the recent research is according to the data before 2006. Thus, the conclusion of the study will be limited by the age of study.

It indicates the feasibility in the future to analyze literature characteristics gathered from the publications from 2000-2012 of management science and engineering statistically. Here, literature measurement analysis method could be used in the process, including employ data to describe the growth trend of literature, rules of periodical distribution and literature subject distribution, etc. Method called "common-word analysis" rather than the classification method for key words according to the code of management science and engineering discipline could be introduced to 
analyze the keywords, author and research methods of papers. This method based on co-word network may be helpful to reveal the links between different research objects. Furthermore the main structure, structure of cooperation and index structures in research of knowledge competence could be described.

From the analysis above, it can be seen that the researches about current situation of discipline and research hotspot are increase with the development of information science disciplines in recent years. Because of the complexity of the discipline of management and the large amount of data to be dealt with, application of information science method is still in its infancy in terms of management science and engineering disciplines. The main direction for future research is how to find the suitable research method of information science for management science and engineering.

\section{Acknowledgement}

In this paper, the research was sponsored by the Students Management Foundation of Jiangsu University (Project No. JDXGSB201307).

\section{References}

[1] She Congguo, Xi Youmin. Comparison and analysis of focal points of management science and engineering study between at home and abroad [J]. Studies In Science of Science, 2002, 04: 406-410.

[2] Liu Yunzhong, Xuan Huiyu. An Evaluation of Current State in Industrial Engineering and Engin eering Management [J]. Journal of Industrial Engineering and Engineering Management,2003,03:67 $-71$.

[3]Zhang Shuntang. Hotspot and Topics of Disciplinary Research in Management science and Engi neering [J]. Journal of ShanDong Institute of Business and Technology,2005,05:105-111.

[4]Li Qunxia, Zhang Qun. Comparison and Analysis of Hot Spot and Development trend in Manag ement Science and Engineering research at home and abroad [J].Forum on Science and Technology in China,2006,06:126-130.

[5] Zhang Lingling,Fang Yong,YangTao et al.Focusing Areas of Management Science and Engineering: A Literature Quantitative Analysis [J],Journal of Management,2005,2(4):380-385

[6] Zhang Wei, Li Shuai, Xiong Xiong,et al.Comparison of Hot Areas of Business

Administration Research between the foreign and the domestic based on Literature Metrology [J],

Science of Science and Management of S.\& T., 2006, 27(3): 5-10.

[7] Ji Shaobo, Min Qingfei, Han Weihe.Overview of information systems research in China and international comparison [J],Journal of Management Sciences in China, 2006, 9(2): 76-85.

[8] Mei Shiqang, Qi Ershi, Wang Xueqing. Concepts and Systems of Management Science and Engineering Discipline [J]. Industrial Engineering Journal,2006,02:1-5.

[9] Wang Liangliang, Peng Xiaodong. Content analysis of the development trends of management sciences__ research in China and at abroad[J]. Studies in Science of Science,2007, 05: 959-962.

[10] Wang Lanpu, Yang Changming, Wang Jun. Co-word Clustering Analysis on Management Science and Engineering Doctoral Dissertations [J]. Commercial Times,2012,17:121-123. [11] Du Nannan, Zong Qianjin, Yuan Qinjian. Research Fields and Trends in the Discipline of Management Science and Engineering [J]. Journal of Intelligence,2012,12:46-50. 